\title{
Portuguese Colonial War veterans' physical health: A systematic review
}

\author{
Ângela Maia ${ }^{1} \&$ Diogo Morgado ${ }^{1}$ \\ ${ }^{1}$ Centro de Investigação em Psicologia da Universidade do Minho, Departamento de Psicologia Aplicada, \\ Universidade do Minho, Braga, Portugal.
}

\begin{abstract}
After 45 years, little is known about Portuguese Colonial War veterans' physical health. This systematic review aimed to fill this gap. Following PRISMA guidelines, searches were conducted, on November 2018, in seven electronic databases for the inclusion of Portuguese or English quantitative, qualitative, or mixed-method published studies, unpublished master's or doctoral theses and research reports that focused on physical health. Seventy-one studies were identified; 10 were considered eligible. Veterans reported several physical complaints and chronic diseases, as well as risk behaviors and health services use for the relief of psychological symptoms. Differences were found between veterans and nonveterans, and veterans with and without posttraumatic stress disorder (PTSD). Combat exposure and PTSD were associated with physical morbidity, in which PTSD was a full mediator. Implications for practice and recommendation for future research are discussed.
\end{abstract}

\section{Keywords: Portuguese Colonial War; veterans; physical health; systematic review.}

A saúde física dos ex-combatentes da Guerra Colonial Portuguesa: Uma revisão sistemática: Após 45 anos, pouco se sabe sobre a saúde física dos ex-combatentes da Guerra Colonial Portuguesa. Esta revisão sistemática tentou preencher esta lacuna. Seguindo as diretrizes PRISMA, foram realizadas pesquisas, em Novembro de 2018, em sete bases eletrónicas para a inclusão de estudos quantitativos, qualitativos, ou mistos publicados em Português ou Inglês, teses de mestrado ou doutoramento e relatórios de investigação não publicados que focaram na saúde física. Setenta e um estudos foram identificados; 10 foram considerados elegíveis. Os ex-combatentes relataram várias queixas físicas e doenças crónicas, bem como comportamentos de risco e o uso de serviços de saúde para a redução de sintomas psicológicos. Foram encontradas diferenças entre ex-combatentes e não-combatentes, e excombatentes com e sem perturbação pós-stress traumático (PPST). Exposição a combate e PPST estavam associadas a morbilidade física, sendo que a PPST foi um mediador total. Implicações para a prática e recomendação para investigações futuras são discutidas.

Palavras-chave: Guerra Colonial Portuguesa; ex-combatentes; saúde física; revisão sistemática.

Between 1961 and 1974, about one million Portuguese soldiers (10\% of the population) were involuntarily mobilized to three separate theaters of operations (i.e., Angola, Guinea-Bissau and Mozambique) in order to fight against liberation movements (who sought self-determination and independence) and maintain these former Portuguese colonies (Maia, McIntyre, Pereira, \& Fernandes, 2006). This military conflict is commonly referred to as the Portuguese Colonial War (PCW). Several studies have shown that, during this period, many soldiers were exposed to a number of potentially traumatic events (Albuquerque, Fernandes, Saraiva, \& Lopes, 1992; Albuquerque \& Lopes, 1994; Ferrajão, 2017; Maia, McIntyre, Pereira, \& Ribeiro, 2011; Silva et al., 2010). For example, according to Maia et al. (2011), in a study with 350 PCW veterans, 63\% of the veterans reported that their lives were threatened during combat situations; $67 \%$ reported witnessing comrades being killed in combat; $56 \%$ saw corpses of comrades; $33 \%$ moved dead bodies; $44 \%$ of the veterans reported being victims of grenades or mines, $40 \%$ reported injuries, $16 \%$ witnessed civilian casualties, $10 \%$ moved civilian bodies, $16 \%$ saw enemy bodies and $13 \%$ moved them. Despite some difficulties in finding statistical reports from the Portuguese army forces, there is some agreement that after the political change in 1974 and the end of the dictatorship, 40.000 soldiers were injured and 10.000 lost their lives during this military conflict (Maia et al., 2006).

\footnotetext{
1 Correspondence address: Diogo Morgado, EPsi, Universidade do Minho, Campus de Gualtar, 4710-057, Braga. E-mail: diogo8morgado@gmail.com. This study was conducted at the Psychology Research Centre (PSI/01662), School of Psychology, University of Minho, and supported partially by the Portuguese Ministry of National Defense under the reference UMINHO/BI/173/2018. The authors wish to thank the Ministry of National Defense for partially funding this project.
} 
For those who survived, many reported chronic psychological disturbances, including posttraumatic stress disorder (PTSD) (i.e., a trauma and stress related disorder composed of intrusive, avoidance, negative alterations in cognitions and mood, and alterations in arousal and reactivity symptoms that may arise after exposure to one or more traumatic events; see American Psychiatric Association [APA], 2013), depression, or substance abuse (e.g., Albuquerque et al., 1992; Albuquerque \& Lopes, 1994; Ferrajão, 2017; Maia et al., 2011; Pereira, Pedras, \& Lopes, 2012; Pereira, Pedras, Lopes, Pereira, \& Machado, 2010). For example, in a sample of 230 PCW veterans, Pereira et al. (2010) found that $40 \%$ reported enough criteria for PTSD diagnosis, and $81 \%$ presented psychopathology. Another study, with a sample of 101 PCW veterans, showed that $71 \%$ of veterans presented psychopathology; $47 \%$ presented severe depression, high-state and trait anxiety, and $45 \%$ fulfilled criteria for a PTSD diagnosis (Pereira et al., 2012). Compared to the Vietnam War (VW), Albuquerque et al. (1992) showed that the incidence of chronic psychological disturbances in PCW veterans was seven times greater than in VW veterans. Through VW data (i.e., duration, total number of troops involved, troops in combat, chronic psychological disturbances), provided by the Center of Disease Control (CDC) and the PCW data, provided by the Portuguese Army Staff, the authors estimated that 140.000 PCW veterans suffered from chronic psychological disturbances, whereas 500.000 VW veterans suffered from the same conditions. Considering the similarities of both wars (guerrilla warfare characterized by raids, ambushes, sabotage, irregular tactics), and the total population of each country, the authors concluded that the PCW had a greater and a major psychological impact on Portuguese veterans' lives. The relationship between combat exposure (e.g., life threatening combat situations, see Keane et al., 1989) and veterans' mental health decline, (e.g., PTSD) has also been shown in international samples including those who fought in the Gulf war or the Iraq and Afghanistan war (Hassija, Jakupcak, Maguen, \& Shipherd, 2012).

The relationship between combat exposure and veterans' mental health, especially PTSD, has been one of the most studied areas in trauma literature. However, the impact of combat exposure on veterans' physical health, namely, physical morbidity (physical symptoms, chronic diseases), health behaviors (risk behaviors), and the need of health services use, has only been a recent relevant research subject (Maia et al., 2011). Overall, among diverse veteran samples who have fought in different war theaters (e.g., Vietnam, Iraq, Afghanistan), research has shown a significant association between combat exposure and physical complaints (e.g., fatigue, headaches, muscular pain, somatic pain) (Bourn, Sexton, Raggio, Porter, \& Porter, 2016; Buttner et al., 2017), chronic diseases (e.g., cardiovascular, gastrointestinal, musculoskeletal, metabolic diseases) (Dursa, Barth, Schneiderman, \& Bossarte, 2016), risk behaviors (e.g., smoking, sedentarism) (Buckley, Mozley, Bedard, Dewulf, \& Greif, 2004) and higher health service use (Agha, Lofgren, VanRuiswyk, \& Layde, 2000).

Similarly, PTSD reveals to be one of the most important factors for the report of physical morbidity, after combat exposure (Osório, Carvalho, Fertout, \& Maia, 2012). For example, Osório et al. (2012) found a significant relationship between PTSD and physical morbidity (e.g., fatigue, respiratory diseases) in a sample of 113 Portuguese Army Special Operation forces deployed in Afghanistan. In addition to physical morbidity, several studies have shown that veterans, particularly those with PTSD diagnosis (Lehavot, Der-Martirosian, Simpson, Shipherd, \& Washington, 2013), are more likely to engage in risk behaviors (Cucciare, Darrow, \& Weingardt, 2011) and to use different health services compared to nonveterans (Frenk, Sautter, Woodring, \& Kramarow, 2017).

Despite the results regarding trauma exposure and PTSD symptomatology, no conclusive evidence was found regarding whose variable better explains the onset of physical health problems. On the one hand, Schnurr and Green (2004) proposed that PTSD could be a key mechanism through which trauma leads to poor physical health. In fact, research has shown a significant relationship between combat exposure and physical health through the mediating role of PTSD (Schnurr \& Spiro, 1999). Alternately, prior research focused on the more direct role of trauma on physical health has suggested that it may be the cumulative effect of multiple lifetime traumas that explains the onset of adverse health outcomes (e.g., cardiovascular diseases, pain conditions) (Weiss, 2007). For instance, Sledjeski, Speisman, and Dierker (2008), using data from the National Comorbidity Survey-Replication (NCS-R), showed that multiple traumas had a cumulative effect on physical health in a nationally representative community of US citizens. This result supports prior research suggesting that the impact of trauma on physical health may be independent of PTSD symptomatology.

Other mechanisms (i.e., biological, behavioral, and psychological) may explain the relationship between war-related PTSD (i.e., military personnel who were exposed to combat exposure and subsequently developed PTSD symptoms) and physical morbidity (Schnurr \& Green, 2004). First, the permanent alteration of biological systems and the excessive or deficient activation of the stress response (i.e., allostatic load) (McEwen, 2000) can trigger the onset of chronic diseases, as well as the progressive incapacitation of the organism to deal effectively with situations of uncertainty and stress, thus creating a 
vicious cycle (Peters, McEwen, \& Friston, 2017). Research has shown a significant relationship between war-related PTSD and the deregulation of these biological systems (e.g., increased cortisol, noradrenaline, cytokine), thus contributing to the increase in physical morbidity, including chronic pain and tiredness (Nakamura et al., 2017), cardiovascular diseases (Edmondson \& von Känel, 2017), autoimmune diseases (Boscarino, 2004), chronic pain and tiredness (Nakamura et al., 2017). Second, the adoption of risk behaviors can also trigger the onset of physical morbidity. Research has shown that, regardless of the theater of operations (e.g., Iraq War, Afghanistan), veterans with PTSD symptoms report more substance abuse (e.g., alcohol, tobacco) (Durai et al., 2011), and sedentarism (Klingaman et al., 2016; Ismaeel et al., 2018), compared to veterans without PTSD symptoms. In turn, these risk behaviors are associated with a greater report of physical morbidity and use of health services (Durai et al., 2011). The adoption of these risk behaviors may constitute a short-term functional avoidance strategy (e.g., self-medication, alcohol abuse) to deal with emotional (e.g., depression, anxiety, stress) (Ismaeel et al., 2018; McDevitt-Murphy, Fields, Monahan, \& Bracken, 2015), and psychological problems (e.g., intrusive thoughts, cognitive biases) (Cucciare et al., 2011) experienced by veterans who were exposed to trauma and have PTSD. In line with these findings, studies with PCW veterans found that alcohol and tobacco consumption were the most reported strategies for coping with discomfort and intrusive thoughts associated with trauma (e.g., Ferrajão, 2017, Maia et al., 2006). Finally, psychological mechanisms, such as abnormal stimulus processing could be an important psychological explanation for the onset of veterans' physical morbidity (McFarlane, Weber \& Clark, 1993). Subjects with PTSD symptoms may interpret reactive changes (cardiovascular reactivity, sleep, adrenergic regulation) as signs of physical illness, which, in turn, can negatively influence their health beliefs (e.g., Hoge, Terhakopian, Castro, Messer, \& Engel, 2007; Beckham et al., 1998). This process can be exacerbated in the presence of negative emotions (e.g., depression, hostility).

Several systematic reviews presented data about male and female veterans' physical health who fought in Vietnam, Iraq and Afghanistan (Qureshi, Pyne, Magruder, Schulz, \& Kunik, 2009; Tansey, Raina, \& Wolfson, 2012). However, no systematic review, to our knowledge, was conducted with the purpose to synthesize the key findings about PCW veterans' physical health. This reveals to be a major gap in the literature given that the PCW has ended 45 years ago, with no clear information about the physical health status of this population. Furthermore, it is clinically and theoretically relevant to identify the factors that may influence veterans' poor physical health, as well as factors that could explain the association between combat exposure and physical health, and the association between PTSD and physical health. This approach could be important for establishing appropriate clinical assessments, adequate referrals and clinically useful evidence-based psychological interventions in response to PCW and future Portuguese veteran population needs. Considering this gap in the literature, the main objectives of the present review were to: i) characterize the PCW veterans' physical health based on the results of the included studies; ii) verify the relationship between combat exposure and physical health; iii) verify the relationship between PTSD and physical health; iv) analyze the comparison results between PCW veterans with and without PTSD diagnosis in relation to physical health; and v) analyze the comparison results between PCW veterans and general population in relation to physical health. In accordance with the literature, key search terms for physical health in the present review were: physical symptoms, chronic diseases, risk behaviors, and health services use. The objectives of this systematic review were defined from the research question: "What is known in the literature about PCW veterans' physical health?".

\section{METHOD}

\section{Eligibility criteria}

The inclusion criteria were: a) quantitative, qualitative or mixed-method studies published in peerreviewed journals; b) unpublished master's or doctoral theses, unpublished research reports, or chapters of books presenting PCW veterans' physical health findings from empirical studies; c) study samples comprising only PCW veterans, or with a control group (i.e., nonveterans) vs. an experimental group (i.e., PCW veterans); d) focus on physical health topics, including characterization of PCW veterans' physical health; the impact of combat exposure, or PTSD, on physical health dimensions (i.e., physical complaints, chronic diseases, risk behaviors, health services use); or comparison between groups (PCW veterans vs. nonveterans; PCW veterans with vs. without PTSD diagnosis) in relation to physical health; and e) studies written in Portuguese or English. Minimum sample sizes, study design or publication year were not stipulated. Articles were excluded if they were in a language other than Portuguese or English; were meta-analysis, systematic reviews, conference articles, opinion articles, posters, chapters of books not presenting PCW veterans' physical health findings from empirical studies, abstracts, empirical studies 
without PCW veteran samples, and studies that did not assess any physical health topic, or with poor clarity of information.

\section{Information sources and search strategy}

In November of 2018, relevant studies were identified by one reviewer (DM) through seven electronic databases: Web of Science/MedLine, PubMed, Scopus, PsycINFO, PsycARTICLES, SciELO, and ScienceDirect. The search terms were equal to all databases. For example, the following search equation was selected in PubMed: ("Portuguese Colonial War" OR "Ultramar War") AND ("War exposure [MeSH]" OR "Combat exposure") AND ("PTSD [MeSH]" OR "Posttraumatic stress [MeSH]") AND ("Veterans Health [MeSH]" OR "Physical Health" OR "Physical Symptoms" OR "Chronic Illness* [MeSH]" OR "Disease* [MeSH]" OR "Risk Behaviors [MeSH]" OR "Healthcare Utilization [MeSH]" OR "Healthcare patients acceptance [MeSH]"). Searches were also conducted on Google Scholar for the inclusion of gray literature (i.e., master's and doctoral theses, and research reports). Database searches were supplemented by a bibliographic review of identified articles, as well as consultation with experts on this topic. There was no time interval restriction during the search strategy. However, we restricted the search strategy only to English and Portuguese language.

\section{Study selection}

Identified studies were imported into the Mendeley program and the duplicates were removed. Titles and abstracts were screened by one reviewer (DM), who proceeded to include possible relevant studies. Full-text articles were analyzed by two reviewers (AM and DM), to ensure that the inclusion criteria were fulfilled. All doubts were discussed between the two reviewers until a consensus was reached.

\section{Data extraction}

Data from the included studies were independently extracted by two reviewers (AM and DM). For each study, we first identified the author(s) name(s), year of publication and study design. Details about the sample size $(N)$ and the main socio-demographic characteristics of the study samples, including PCW veterans and control groups (i.e., nonveterans) were then collected (i.e., mean age; education level, marital status, war theater). Details about the study procedures were also abstracted (i.e., location of sample recruitment). Subsequently, we identified the physical health dimensions (i.e., physical complaints, chronic diseases, risk behaviors, health services use) assessed by the included studies and extracted how they were measured within each study (e.g., self-report measures). Details about how combat exposure or PTSD was measured within each study was also noted. Statistical analysis of the eligible studies were also abstracted. Finally, we extracted the main results regarding PCW veterans' physical health. Specifically, we extracted descriptive statistics of the physical health variables (i.e., frequency, severity), correlations among the key measures, regression analysis and mediation analysis. Regarding these analysis, the results that showed statistical significance, as well as the null findings were extracted by the two reviewers. All disagreements between reviewers were solved after discussion and consensus. Description of main sample features, study design and procedures are presented in Table 1, whereas description of combat exposure, PTSD and physical health measures, statistical analysis, and key results of the eligible studies are presented in Table 2.

\section{Risk of bias in individual studies}

The risk of bias in individual studies was independently conducted by two reviewers (AM and DM). We used the Quality Assessment Tool for Observational Cohort and Cross-Sectional Studies checklist of 14 items (National Institute of Health, 2016) for the assessment of quantitative studies, and the Critical Appraisal Skills Programme Qualitative checklist of 10 items (CAPS, 2013) for the assessment of qualitative studies. All items from the two checklists were utilized, and each study was independently assigned an overall quality rating ("Good", "Fair", or "Poor") by the two reviewers (Table 3 and 4). Included studies with a rating of poor quality translates to a high risk of bias, whereas a rating of good quality translates to a low risk of bias. Potential risk of bias may include selection bias, information bias, measurement bias, or confounding (National Institute of Health, 2016). Quality ratings were not used to exclude studies, but did serve to identify consistent weaknesses and risk of bias from eligible studies. Inter-rater agreement (or inter-rater reliability) was measured through Cohen's kappa coefficient $(\kappa)$, a robust statistic that measures the degree of agreement between two raters regarding the same qualitative (categorical) items, while taking into account chance agreement. (McHugh, 2012). Cohen's kappa magnitude can range from -1 to +1 , where $\leq 0$ represents no agreement; $0.01-0.20$ represents none to slight agreement; 0.21-0.40 represents fair agreement; 0.41-0.60 represents moderate agreement; 0.61 - 
0.80 represents substantial agreement; and 0.81-0.99 represents almost perfect agreement, and 1 represents perfect agreement (McHugh, 2012). Inter-rater agreement analysis was performed using the IBM SPSS, version 25 for Windows (United States, New York, IBM Corporation).

\section{Data synthesis}

Included articles were reviewed in a qualitative synthesis. Key findings were organized in different categories in a discrete and no overlapping manner. In each category, the findings were summarized and highlighted their significance.

\section{RESULTS}

We initially identified 67 studies through electronic database searching. After the duplicates were removed $(n=21)$, the titles and abstracts were screened. After the screening process, 39 studies were excluded. The main reasons for the studies exclusion were: i) did not include PCW veteran samples $(n=$ 17); ii) did not assess any dimension of physical health $(n=17)$; and iii) were systematic reviews $(n=3)$, scientific presentations (i.e., posters) $(n=1)$; and conference articles $(n=1)$. Of the seven full-text articles assessed for eligibility, six met the inclusion criteria. One study was excluded because it presented unclear data regarding the report of risk behaviors in a sample of PCW veterans. Moreover, this study did not assess other physical health dimensions. References of these six eligible studies were manually analyzed, resulting in three additional studies (Albuquerque, Fernandes, Saraiva, \& Lopes, 1992; Couto, 2007; Maia et al., 2006). Finally, an additional study was identified through contact with subject matter experts (Albuquerque \& Lopes, 1994). In total, 71 studies were identified in this systematic review, in which 10 were considered eligible (Fig.1).

\section{Characteristics of included studies}

Year of publication and sample sizes. The total amplitude of included studies ranged between 1992 and 2017. The sample sizes of the included studies varied between 40 (e.g., Albuquerque et al., 1992; Ferrajão, 2017) and 575 (Silva et al., 2010). Eight studies presented only PCW veteran samples, whereas two studies presented also nonveteran samples (Começanha \& Maia, 2011; Couto, 2007).

Sample characteristics. Sample characteristics of included studies showed that the mean age of veteran' samples varied between 41 and 65 years. The majority of veterans reported being married, with a 4-year schooling education. Angola was the most reported theater of war. In comparison with veteran' samples, nonveterans samples presented the same age cohort, were also mostly married, and with the same level education (i.e., 4-year schooling education).

Design. All studies presented a cross-sectional design. Nine studies were quantitative, whereas one was qualitative (Ferrajão, 2017). Regarding the quantitative studies, all presented a descriptive design, three studies presented also a correlation design (Começanha \& Maia, 2011; Maia et al., 2011; Pereira et al., 2012), and four studies presented also comparative research (Começanha \& Maia, 2011; Couto, 2007; Pereira et al., 2010, 2012).

\section{Procedures}

Veteran samples were recruited from Veterans' associations (Albuquerque \& Lopes, 1994; Couto, 2007; Maia et al., 2006, 2011; Pereira et al., 2010, 2012), clinical centers specialized in the treatment of war veterans (Ferrajão, 2017), psychiatric public hospitals (Albuquerque et al., 1992; Albuquerque \& Lopes, 1994; Pereira et al., 2010, 2012), health institutions (Albuquerque \& Lopes, 1994; Começanha \& Maia, 2011), and from processes elaborated by the Department of Justice Defense and biographical elements from the army general archive (Silva et al., 2010).

\section{Measures}

Six studies used only self-report measures to assess physical complaints (Maia et al., 2011; Couto, 2007), chronic illnesses (Maia et al., 2011), risk behaviors (Couto, 2007; Maia et al., 2006), physical quality of life (Pereira et al., 2010, 2012), and health services use (Começanha \& Maia, 2011). In addition to these self-report measures, three studies conducted a clinical evaluation to assess physical complaints and chronic diseases (Albuquerque et al., 1992; Albuquerque \& Lopes, 1994; Pereira et al., 2010) and risk behaviors (Albuquerque et al., 1992; Albuquerque \& Lopes, 1994). One study conducted two semistructured interviews for the assessment of physical complaints and health services use (Ferrajão, 2017). Finally, one study used processes (i.e., documents that verify the existing conditions for the attribution of 
the Armed Forces Deficiency status in veterans who claim mental disturbance resulting from the war) elaborated by the Portuguese Ministry of National Defense, in the context of Military Hospitals, as well as biographical elements provided by the Army General Archive to assess physical complaints and chronic diseases (Silva et al., 2010).

Regarding the assessment of combat exposure, four studies used self-report measures (Começanha \& Maia, 2011; Couto, 2007; Maia et al., 2006, 2011); two studies conducted a clinical evaluation (Albuquerque et al., 1992; Albuquerque \& Lopes, 1994); and one study used processes and biographical elements provided by the Army General Archive (Silva et al., 2010).

Regarding the assessment of PTSD, seven studies used self-report measures (Albuquerque et al., 1992; Começanha \& Maia, 2011; Couto, 2007; Maia et al., 2006, 2011; Pereira et al., 2010, 2012); four studies conducted a clinical evaluation for the confirmation of PTSD diagnosis (Albuquerque et al., 1992; Albuquerque \& Lopes, 1994; Pereira et al., 2010, 2012); one study confirmed the PTSD diagnosis using the Clinician-Administered PTSD Scale (CAPS) (Ferrajão, 2017); and one study used processes and biographical elements provided by the Army General Archive (Silva et al., 2010). Characteristics and main results are summarized in Tables 1 and 2 .

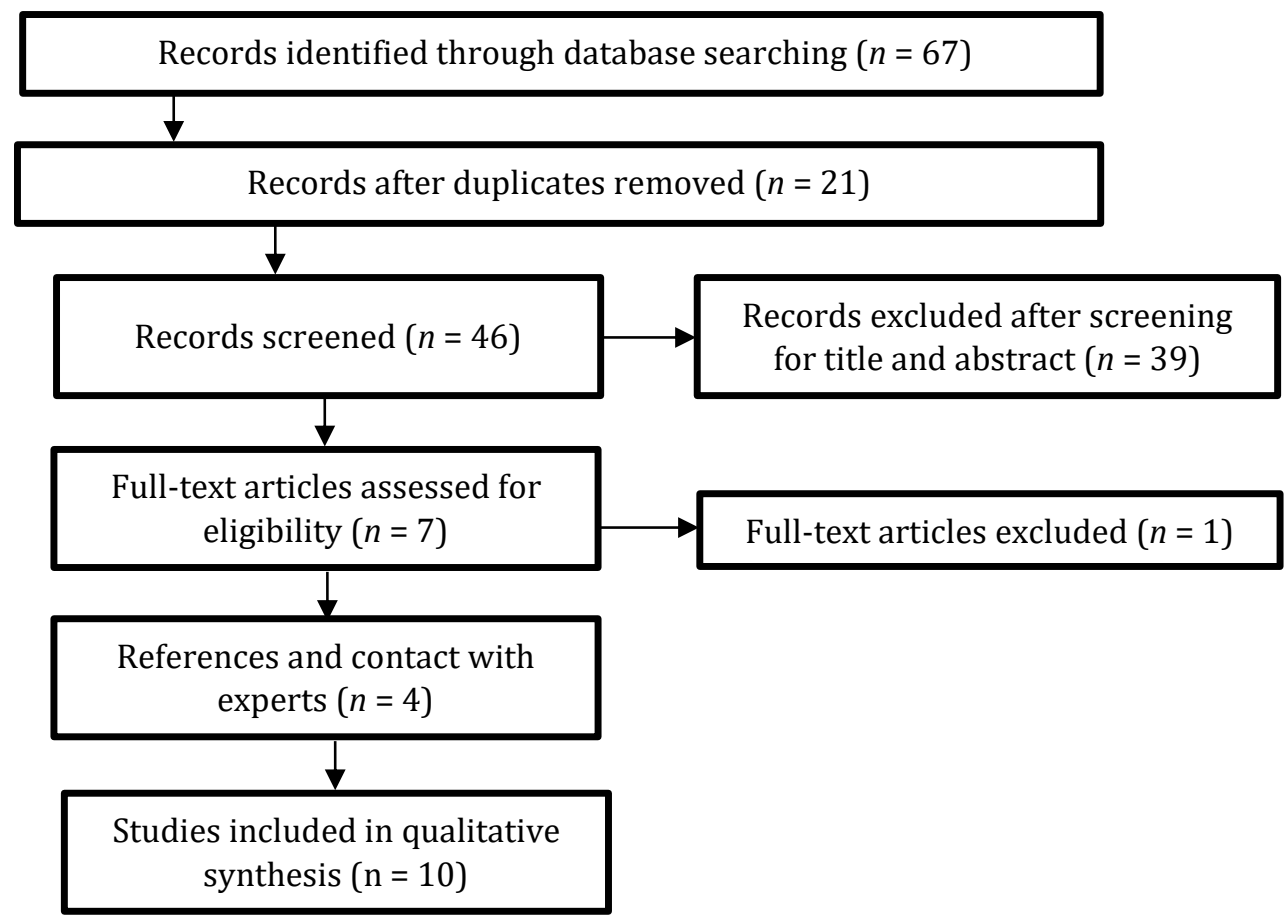

Figure 1. Flow diagram of the article selection

\section{Risk of bias of included studies}

Quality appraisal of each criterion of the included studies is presented in detail in Table 3 and 4 . The main sources of bias were: i) all studies presented a cross-sectional design thus preventing determination of causality between variables; ii) few studies reported the participation rate (Começanha \& Maia, 2011; Maia et al., 2006, 2011). This increases the risk of bias because if fewer than $50 \%$ of eligible subjects participated in the studies, then there is concern that the studies population may not adequately represent the target population; iii) all studies did not present any justification of sample size or power description, neither provided effect estimates or variance. This increases the risk of bias because it is not clear whether or not the studies had enough participants to detect an association if one truly existed; iv) lack of representativeness in all studies due to convenience sampling; v) the majority of studies relied only on self-report measures for the assessment of physical health dimensions, thus including possible reporting bias. Furthermore, two studies did not present any detailed information about the measures used (e.g., lack of psychometric properties, type of response to the item - Likert or dichotomous response) (Albuquerque et al., 1992; Albuquerque \& Lopes, 1994). Likewise, all self-report measures that assessed veterans' physical health were adapted (with values of good internal consistency) but not validated for the PCW veteran population. There was great inter-rater agreement among the reviewers, $\kappa$ $=.82$ (95\% CI, .75 to .90), $p=.001$, and doubts were discussed until a consensus was reached. A final overall quality rating for each study is presented in Table 3 and 4. 
Table 1. Description of main sample characteristics, study design and procedures.

\begin{tabular}{|c|c|c|c|c|}
\hline Authors (Year) & Sample size $(n)$ & $\begin{array}{l}\text { Sample characteristics } \\
\text { (Mean age; education level, marital status, } \\
\text { war theater) }\end{array}$ & Design & Procedures (recruitment) \\
\hline $\begin{array}{l}\text { Albuquerque et al. } \\
\text { (1992) }\end{array}$ & $\begin{array}{l}40 \text { PCW veterans with } \\
\text { PTSD diagnosis. }\end{array}$ & $\begin{array}{l}M=41 \text { years, } S D=\mathrm{NR} . \\
\text { Education level = NR. } \\
\text { Married = 57.5\%; Single = 25\%; Divorced = } \\
17.5 \% \text {; Widowed = NR. } \\
\text { Angola }=40 \% . \\
\text { Guinea Bissau }=35 \% . \\
\text { Mozambique }=20 \% .\end{array}$ & $\begin{array}{l}\text { A cross-sectional, } \\
\text { descriptive study. }\end{array}$ & Sample recruited from a psychiatric public hospital. \\
\hline $\begin{array}{l}\text { Albuquerque \& Lopes } \\
\text { (1994) }\end{array}$ & $\begin{array}{l}120 \text { PCW veterans with } \\
\text { PTSD diagnosis. }\end{array}$ & $\begin{array}{l}M=46 \text { years, } S D=\mathrm{NR} . \\
\text { Education level }=\mathrm{NR} . \\
\text { Married }=83.3 \% ; \text { Single }=9.2 \% \text {; Divorced }= \\
6.7 \% ; \text { Widowed }=0.8 \% . \\
\text { Angola }=42.6 \% . \\
\text { Guinea Bissau }=28.7 \% . \\
\text { Mozambique }=27 \% .\end{array}$ & $\begin{array}{l}\text { A cross-sectional, } \\
\text { descriptive study. }\end{array}$ & $\begin{array}{l}\text { Sample recruited from ADAF, psychiatric public hospital, } \\
\text { and health institutions. }\end{array}$ \\
\hline $\begin{array}{l}\text { Começanha \& Maia } \\
\text { (2011) }\end{array}$ & $\begin{array}{l}25 \text { PCW veterans and } 25 \\
\text { nonveterans } \\
\text { (with the same age } \\
\text { cohort). }\end{array}$ & $\begin{array}{l}M=59 \text { years, } S D=2.73 . \\
\text { 6-year schooling }=46 \% . \\
\text { Married }=90 \% \text {; Single = NR; Divorced = NR; } \\
\text { Widowed }=\text { NR. } \\
\text { Angola }=42 \% . \\
\text { Guinea Bissau }=20 \% . \\
\text { Mozambique }=38 \% .\end{array}$ & $\begin{array}{l}\text { A cross-sectional, } \\
\text { correlational and } \\
\text { comparative study. }\end{array}$ & Sample recruited from a health institution. \\
\hline $\begin{array}{l}\text { Couto } \\
(2007)\end{array}$ & $\begin{array}{l}350 \text { PCW veterans and } \\
81 \text { nonveterans (with } \\
\text { the same age cohort). }\end{array}$ & $\begin{array}{l}\text { Veterans: } M=57 \text { years, } S D=3.69 . \\
\text { 4-year schooling = } 68.3 \% . \\
\text { Married = 92\%; Single = NR; Divorced = NR; } \\
\text { Widowed = NR. } \\
\text { War theater = NR (see Maia et al., } 2006 \text { ). } \\
\text { Nonveterans: } M=58 \text { years, } S D=3.99 . \\
\text { 4-year schooling = 50\%. } \\
\text { Married = } 84.6 \% \text {; Single = } 2.6 \% \text {; Divorced = } \\
6.2 \% \text {; Widowed }=2.6 \%\end{array}$ & $\begin{array}{l}\text { A cross-sectional, } \\
\text { descriptive and } \\
\text { comparative study. }\end{array}$ & $\begin{array}{l}\text { Veteran sample was recruited from a list of } 35,000 \\
\text { members of a Veterans' association, which covered } \\
\text { residents in all continental Portugal (original sample } \\
\text { from the study of Maia et al. (2006)). } \\
\text { Nonveteran sample recruited by phone contact. } \\
\text { Administration of self-report measures in a public } \\
\text { university). }\end{array}$ \\
\hline $\begin{array}{l}\text { Ferrajão } \\
(2017)\end{array}$ & $\begin{array}{l}20 \text { PCW veterans } \\
\text { diagnosed with PTSD } \\
\text { and } 20 \text { PCW veterans } \\
\text { without PTSD. }\end{array}$ & $\begin{array}{l}M=64 \text { years, } S D=\text { NR. } \\
\text { 4-year schooling = 55\%. } \\
\text { Married = NR; Single = NR; Divorced = NR; } \\
\text { Widowed = NR. } \\
\text { Angola = NR. } \\
\text { Guinea Bissau = NR. } \\
\text { Mozambique = NR. }\end{array}$ & $\begin{array}{l}\text { A cross-sectional, } \\
\text { qualitative study. }\end{array}$ & $\begin{array}{l}\text { Sample recruited from two clinical centers specialized in } \\
\text { the treatment of war veterans. }\end{array}$ \\
\hline
\end{tabular}


Married $=92 \%$; Single $=2 \%$; Divorced $=4 \%$

Widowed $=2 \%$.

Angola $=45 \%$

Guinea Bissau $=$ NR.

Mozambique $=$ NR.

Maia et al.

Pereira et al

Pereira et al

Silva et al. (2010)
350 PCW veterans.

$M=57$ years, $S D=3.69$.

4 -year schooling $=68 \%$

Married $=92 \%$; Single $=2 \%$; Divorced $=4 \%$; Widowed $=2 \%$.

Angola $=\mathrm{NR}$

Guinea Bissau $=$ NR.

Mozambique $=$ NR.

(see Maia et al., 2006).

101 PCW veterans who $\quad M=59$ years, $S D=$ NR.

were in an evaluation

process for the request

of medical/social

support (with the same

age cohort).

230 PCW veterans who were in an evaluation

process for the request

of medical/social

support (with the same age cohort).

4-year schooling $=82 \%$.

Married $=92 \%$; Single $=$ NR; Divorced $=$ NR

Widowed $=$ NR.

Angola $=41 \%$.

Guinea Bissau $=30 \%$.

Mozambique $=28 \%$.

$M=\mathrm{NR}, S D=\mathrm{NR}$ (authors reported that most veterans $(80.8 \%)$ had an age between 56 and

65 years old).

4-year schooling $=77.8 \%$.

Married $=90.9 \%$; Single $=1.3 \%$; Divorced $=$

$6.1 \%$; Widowed $=1.7 \%$

Angola $=42.6 \%$

Guinea Bissau $=28.7 \%$

Mozambique $=27 \%$.

575 PCW veterans who had single or multiple

trauma injuries. These

veterans were in an

evaluation process for

the request of

social/medical support

(with the same age

cohort). Widowed $=$ NR.
A cross-sectional and descriptive study.

Research project funded

by Fundação para a

Ciência e Tecnologia.

\section{A cross-sectional,}

descriptive and

correlational study.

Cross-sectional,

correlational and

comparative study.

A cross-sectional,

descriptive and

comparative study.

Sample recruited from a list of 35,000 members of a Veterans association which covered residents in all continental Portugal.

Sample recruited from a list of 35,000 members of a Veterans association, which covered residents in all continental Portugal.

Sample recruited from a psychiatry department of a central public hospital and from a veteran's organization, both in the north of Portugal.

Sample recruited from a psychiatry department of a central public hospital and from a veteran's organization, both in the north of Portugal.

A cross-sectional, descriptive report conducted for National Education Level $=\mathrm{NR}$

Married $=$ NR; Single $=$ NR; Divorced $=$ NR

Angola $=$ NR .

Guinea Bissau $=$ NR.

Mozambique $=\mathrm{NR}$ Ministry of Defense.
Sample selected from processes elaborated by the Department of Justice Defense and biographical elements provided by the army general archive.

Note. ADAF = Association of Disabled Armed Forces; NR = Not Reported; PCW = Portuguese Colonial War; PTSD = Posttraumatic Stress Disorder. 
Table 2. Description of combat exposure, PTSD and physical health measures, statistical analysis, and main results of the eligible studies.

\section{Authors (Year)}

Albuquerque et al

Combat exposure

(measure)

Clinical evaluation

NR self-report

measures.

PTSD (measure)

(measure)

Clinical evaluation NR self-report

measures.

(1994)

Clinical evaluation.

PTSS- 10.

EIS.

Physical health problems

Clinical evaluation; NR

self-report measures.

Risk behaviors:

Clinical evaluation; NR

self-report measure.

Clinical evaluation. Clinaluation

NR self-report NR self-report measures.

measures.
Statistical Analysis

Descriptive statistics.

\section{Main results}

High incidence of psychosomatic problems (32.5\%) and alcohol dependence and drug use (28\%). The physical

health problems reported were headaches $(n=13)$

gastric ulcer $(n=5)$, tropical disease $(n=4)$

hypertension ( $n=3)$, sexual dysfunction $(n=3)$, dermatological disease $(n=1)$, and cardiovascular disease $(n=1)$.

Descriptive statistics

The main physical health problems reported were headaches $(n=27)$, gastrointestinal diseases $(n=22)$, tropical diseases $(n=20)$, dermatological diseases $(n=$ $10)$, arterial hypertension $(n=9)$, sexual diseases $(n=$ $7)$, atypical algias $(n=4)$, hepatitis $(n=3)$, lipotimias $(n$ $=3)$, buzzing $(n=3)$, diabetes $(n=2)$, and cardiovascular disease $(n=2)$. Veterans also reported alcohol and drug use $(n=25)$.

\section{Começanha \& Maia RTES (first part).}

RTES (second part).

Chronic diseases: SocioDemographic and Clinical Questionnaire

Health services use: SocioDemographic and Clinical Questionnaire.
Descriptive statistics. Mann-Whitney.

Spearman

correlations.
$23(92 \%)$ veterans reported chronic diseases (examples were not given in this study) during the PCW period. Overall, veterans showed a higher rate of chronic diseases $(Z=-4.73, p=.01)$ and health services use $(Z=$ $5.33, p=.01$ ) compared to nonveterans. Specifically, veterans used, more frequently, the health center, public hospital, and specialized consultations. However, no significant differences were found between the groups regarding the use of private clinics.

PTSD was associated with chronic diseases $\left(\mathrm{r}_{\mathrm{s}}=.47, p=\right.$ $.05)$, however no significant association was found between PTSD and health services use.

Physical complaints: RSCL. Descriptive statistics. Mann-Whitney.

Chronic diseases: SocioDemographic and Clinical Questionnaire.

Risk behaviors: QHEC and Socio-Demographic and Clinical Questionnaire.

Veterans showed a higher rate of physical complaints $(Z$ $=-6.44, p=.001)$ and chronic diseases $(Z=-6.96, p=$ 001) compared to nonveterans.

No statistically significant differences were found between groups regarding alcohol $\left(\chi^{2}=914(d f=1), p=\right.$ $.34)$, coffee $\left(\chi^{2}=1,601(\mathrm{df}=1) ; p=.21\right)$, and tobacco consumption $\left(\chi^{2}=1,333(\mathrm{df}=1) ; p=.25\right)$. Similarly, no significant differences were found between groups regarding alcohol $\left(\chi^{2}=2,045(d f=1), p=.15\right)$, coffe $\left(\chi^{2}=\right.$ $.664(d f=1), p=.42)$, and tobacco consumption $\left(\chi^{2}=\right.$ $1.000(d f=1), p=3.17)$ in order to reduce war-related 
discomfort.

Significant differences were found between the groups with regard to the index of health risk behaviors $(\mathrm{Z}=$ $7,772, p=.001)$. Specifically, veterans presented a higher index of adoption of risk-behaviors (e.g., eating habits, substance consumption and physical exercise).

Ferrajão (2017)

NA.

Diagnosis of the

clinical status was

confirmed using the

Physical complaints: Two

semi-structured

Clinician-

Administered PTSD

Scale (CAPS)

interviews.
Maia et al.(2006)

MHQ.

MHQ
Thematic and Categorial Analysis.

All participants suffered from a chronic physiciandiagnosed medical disorder. Eligible participants had two to four cardiometabolic conditions, that is, hypertension ( $n=24)$, type 2 diabetes $(n=31)$, hyperlipidemia $(n=13)$, or congestive heart failure $(n=$ 9).

A greater number of veterans with PTSD $(n=15)$ verbalized physical complaints (e.g., headaches, dizziness) compared with control group $(n=8)$. Similarly, a greater number of veterans with PTSD $(n=$ 18 ) verbalized physical complaints (e.g., headaches, dizziness) compared with control group $(n=5)$.

Veterans reported the need for medical care, the search for a medical specialist, or the request for hospital admission for the relief of psychological symptoms, or avoidance of symptoms associated with potentially traumatic events.

Risk behaviors: QHEC and Descriptive statistics. Socio-Demographic and Clinical Questionnaire.

Physical complaints: RSCL. Descriptive statistics. Chronic diseases: CIC.
RTES.
Spearman Correlation. Regression analysis. Hierarchical

regression analysis Mediation analysis.
$81 \%$ of the sample reported alcohol consumption, $23 \%$ reported tobacco consumption and $88 \%$ reported coffee consumption. The main justification for its use was the relief of discomfort or subjective inquietude.

The main reported physical complaints were chronic pain, fatigue, and sleep problems, whereas the main reported chronic diseases were mental health problems (65\%), gastrointestinal (41\%) and cardiovascular diseases (38\%).

Combat exposure was positively correlated with both physical complaints $\left(R_{s}=.27, p=.01\right)$ and chronic diseases $\left(R_{S}=.29, p=.01\right)$, although current PTSD symptoms presented higher correlations with physical complaints $\left(R_{S}=.48, p=.01\right)$ and chronic diseases $\left(R_{s}=\right.$ $.38, p=.01)$, than war exposure.

In regression analysis, combat exposure was a significant predictor of physical complaints and chronic 
diseases, accounting for $7 \%$ of the variance, respectively. Similarly, PTSD was a significant predictor of physical

complaints and chronic diseases, explaining $2 \%$ and $5 \%$ of the variance, respectively.

All three clusters were significant predictors of reported illnesses: Avoidance had the higher $\Delta \mathrm{R} 2$ (5\%), followed

by re-experiencing the event (3\%) and arousal (2\%). Similarly, all three clusters were significant predictors of physical symptoms. Arousal was the strongest predictor, explaining $3 \%$ of unique variance, followed by avoidance $(2 \%)$ and re-experiencing the event (1\%).

The results, for reported illnesses $(Z=4.79, p<.001)$ and physical symptoms $(Z=5.42, p<.001)$, showed that PTSD was a mediator of the relation between war exposure and health variables.

Pereira et al. (2012)

NA.

RTES.

PTSD diagnosis

confirmed through

clinical evaluation.

Pereira et al. (2010)

NA.

Silva et al. (2010)

Processes by DEJUR and biographical elements provided by the army general archive. and biographical elements provided by the army genera
Physical quality of life: WHOQOL- Bref.

Descriptive statistics. Pearson correlation.

Independent Samples $t$

Test.

Multiple regression

analysis.

Chronic diseases: clinical evaluation through one interview.

Physical quality of life: WHOQOL- Bref.

Processes by DEJUR Chronic diseases: archive.
Processes by DEJUR and

biographical elements

provided by the army

general archive.
Descriptive statistics.

Independent Samples $t$ Test.

Descriptive statistics.

$96(17 \%)$ veterans reported chronic diseases triggered by war-related risk factors (e.g., exposure to high noise) The main chronic diseases were nervous system (30\%), hearing (18.8\%), respiratory $(16.7 \%)$ and digestive diseases.

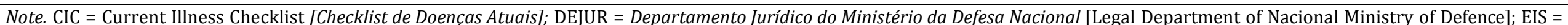

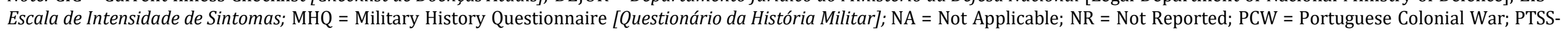

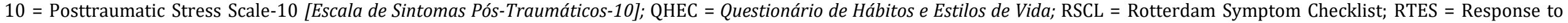

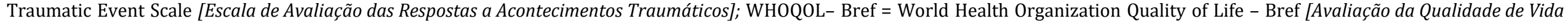
da Organização Mundial de Saúde - Versão Breve]. 


\section{Characterization of the PCW veterans' physical morbidity}

Seven studies presented data regarding PCW veterans' physical morbidity (Albuquerque et al., 1992; Albuquerque \& Lopes, 1994; Começanha \& Maia, 2011; Ferrajão, 2017; Maia et al., 2011; Pereira et al., 2010; Silva et al., 2010). According to these studies, the main physical complaints reported by PCW veterans were headaches, hypertension (Albuquerque et al., 1992; Albuquerque \& Lopes, 1994; Ferrajão, 2017), sexual dysfunction, gastric ulcer (Albuquerque et al., 1992), atypical algias, hepatitis, lipotimias, buzzing (Albuquerque \& Lopes, 1994), low back pain, fatigue (Maia et al., 2011), and sleep problems (Ferrajão, 2017; Maia et al., 2011). PCW veterans also reported several chronic diseases, including cardiovascular (Albuquerque et al., 1992; Albuquerque \& Lopes, 1994; Ferrajão, 2017; Maia et al., 2011; Pereira et al., 2010), gastrointestinal (Albuquerque et al., 1992; Albuquerque \& Lopes, 1994, Maia et al., 2011), dermatological (Albuquerque et al., 1992; Albuquerque \& Lopes, 1994), digestive (Pereira et al., 2010; Silva et al., 2010), tropical (Albuquerque et al., 1992; Albuquerque \& Lopes, 1994; Silva et al., 2010), sexual (Albuquerque \& Lopes, 1994), metabolic (Pereira et al., 2010), nervous system (Silva et al., 2010), hearing (Albuquerque \& Lopes, 1994; Silva et al., 2010), respiratory (Silva et al., 2010) and endocrine (diabetes) diseases (Albuquerque \& Lopes, 1994; Ferrajão, 2017). Two studies presented also data regarding PCW veterans' physical morbidity in comparison with nonveterans with the same age cohort (Começanha \& Maia, 2011; Couto, 2007). These studies showed that PCW veterans reported higher rates of physical complaints and chronic diseases.

\section{Risk behaviors}

Table 3. Risk of bias assessment of included quantitative studies.

\begin{tabular}{lccccccccccccccc}
\hline Study & Q1 & Q2 & Q3 & Q4 & Q5 & Q6 & Q7 & Q8 & Q9 & Q10 & Q11 & Q12 & Q13 & Q14 & Assessment \\
\hline $\begin{array}{l}\text { Albuquerque et al. } \\
\text { (1992) }\end{array}$ & Yes & Yes & NR & Yes & No & No & Yes & NA & No & No & No & No & NA & NA & Poor \\
$\begin{array}{l}\text { Albuquerque \& Lopes } \\
\text { (1994) }\end{array}$ & Yes & Yes & NR & Yes & No & No & Yes & NA & No & No & No & No & NA & NA & Poor \\
$\begin{array}{l}\text { Começanha \& Maia } \\
\text { (2011) }\end{array}$ & Yes & Yes & Yes & Yes & No & No & Yes & NA & Yes & No & Yes & NR & NA & No & Fair \\
Couto (2007) & Yes & Yes & NR & No & No & No & Yes & NA & No & No & Yes & NR & NA & NA & Poor \\
Maia et al. (2006) & Yes & Yes & Yes & Yes & No & No & Yes & NA & NR & No & NR & NR & NA & NA & Fair \\
Maia et al. (2011) & Yes & Yes & Yes & Yes & No & No & Yes & NA & Yes & No & Yes & NR & NA & Yes & Good \\
Pereira et al. (2012) & Yes & Yes & NR & Yes & No & No & Yes & No & Yes & No & Yes & NR & NA & Yes & Fair \\
Pereira et al. (2010) & Yes & Yes & NR & Yes & No & No & Yes & NA & Yes & No & Yes & NR & NA & NA & Fair \\
Silva et al. (2010) & Yes & Yes & NR & Yes & No & No & Yes & NA & No & No & No & NR & NA & NA & Poor \\
\hline
\end{tabular}

Note. NA = Not Applicable; NR = Not Reported; NHLBI = National Heart, Lung, and Blood Institute; Q1 = Was the research question or objective in this paper clearly stated?; Q2 = Was the study population clearly specified and defined?; Q3 = Was the participation rate of eligible persons at least 50\%?; Q4 = Were all the subjects selected or recruited from the same or similar populations (including the same time period)? Were inclusion and exclusion criteria for being in the study prespecified and applied uniformly to all participants?; Q5 = Was a sample size justification, power description, or variance and effect estimates provided?; Q6 = For the analyses in this paper, were the exposure(s) of interest measured prior to the outcome(s) being measured?; Q7 = Was the timeframe sufficient so that one could reasonably expect to see an association between exposure and outcome if it existed?; Q8 = For exposures that can vary in amount or level, did the study examine different levels of the exposure as related to the outcome (e.g., categories of exposure, or exposure measured as continuous variable)?; Q9 = Were the exposure measures (independent variables) clearly defined, valid, reliable, and implemented consistently across all study participants?; Q10 = Was the exposure(s) assessed more than once over time?; Q11 = Were the outcome measures (dependent variables) clearly defined, valid, reliable, and implemented consistently across all study participants?; Q12 = Were the outcome assessors blinded to the exposure status of participants?; Q13 = Was loss to followup after baseline $20 \%$ or less?; Q14 = Were key potential confounding variables measured and adjusted statistically for their impact on the relationship between exposure(s) and outcome(s)?. 
Table 4. Risk of bias assessment of included qualitative studies.

\begin{tabular}{lccccccccccc}
\hline Study & Q1 & Q2 & Q3 & Q4 & Q5 & Q6 & Q7 & Q8 & Q9 & Q10 & Assessment \\
\hline Ferrajão (2017) & Yes & Yes & Yes & Yes & Yes & NR & Yes & Yes & Yes & Yes & Good \\
\hline
\end{tabular}

Note. NR = Not Reported; Q1 = Was there a clear statement of the aims of the research?; Q2 = Is a qualitative methodology appropriate?; Q3 = Was the research design appropriate to address the aims of the research?; Q4 = Was the recruitment strategy appropriate to the aims of the research?; Q5 = Was the data collected in a way that addressed the research issue?; Q6 = Has the relationship between researcher and participants been adequately considered?; Q7 = Have ethical issues been taken into consideration?; Q8 = Was the data analysis sufficiently rigorous?; Q9 = Is there a clear statement of findings?; Q10 = How valuable is the research?.

Four studies showed that the main risk behaviors reported by PCW veterans were alcohol, tobacco, coffee, and drugs use (Albuquerque et al., 1992; Albuquerque \& Lopes, 1994; Couto, 2007; Maia et al., 2006). The main justification for its use was the reduction of war-related discomfort (Couto, 2007; Maia et al., 2006, 2011). In one study (Couto, 2007), no significant differences were found between PCW veterans $(n=350)$ and nonveterans $(n=87)$ in relation to alcohol, tobacco and coffee consumption. However, in this study, PCW veterans had a higher index of adoption of risk behaviors (e.g., substance abuse, sedentary lifestyle, poor diet) compared to nonveterans.

\section{Health services use}

We found only one quantitative study which indicated that PCW veterans $(n=25)$ used, more frequently, the health center, public hospital, and specialized consultations compared to nonveterans $(n=$ 25). However, no significant differences were found between the groups regarding the use of private clinics (Começanha \& Maia, 2011). Despite not having included a sample of nonveterans, a qualitative study indicated that 18 of the 20 PCW veterans with PTSD diagnosis verbalized the need for medical care, namely overuse of medication, in order to help them calm down from posttraumatic symptoms (i.e., feeling explosive or agitated), seeking their psychiatrist's help to change medication for reducing posttraumatic symptoms, or asking for hospitalization to avoid stressful events. In comparison, the need for medical care, the search for a medical specialist, or the request for hospital admission was rarely verbalized by the comparison group (i.e., PCW veterans without PTSD) (Ferrajão, 2017).

\section{Relationship between combat exposure and physical health}

We found only one study that showed a significant positive correlation between combat exposure and physical complaints (e.g., fatigue, sleep problems) and chronic diseases (e.g., cardiovascular, gastrointestinal diseases) in a total sample of 350 PCW veterans (Maia et al., 2011). In addition, combat exposure was a significant predictor of physical complaints and chronic diseases, with higher combat exposure associated with higher number of reported illnesses (Maia et al., 2011).

\section{Relationship between PTSD and physical health}

Two studies with PCW veteran samples showed a significant positive association between PTSD and physical complaints (Maia et al., 2011) and chronic diseases (Começanha \& Maia, 2011; Maia et al., 2011), after the control of potential covariates (i.e., childhood adversity, combat exposure) (Maia et al., 2011). However, PTSD revealed not to be associated with health services use (Começanha \& Maia, 2011), nor with physical quality of life (Pereira et al., 2012). In terms of PTSD-specific clusters, Maia et al. (2011) found that all three clusters (i.e., arousal, avoidance and re-experiencing the event) were significant predictors of physical complaints and chronic diseases. Arousal was the strongest predictor of physical complaints, whereas avoidance was the strongest predictor of chronic diseases. In addition to these results, Maia et al. (2011) found that PTSD was a mediator of the relation between combat exposure and physical complaints and chronic diseases.

\section{Differences between PCW veterans with and without PTSD in relation to physical health}

Two quantitative studies found statistically significant differences between PCW veterans with and without PTSD diagnosis. Specifically, PCW veterans with PTSD diagnosis reported a lower physical quality of life compared to veterans without this disorder (Pereira et al., 2010, 2012). Similarly, one qualitative study showed that a greater number of PCW veterans with PTSD diagnosis $(n=18)$ verbalized physical complaints (e.g., headaches, dizziness) compared with five PCW veterans without this disorder (Ferrajão, 2017). 


\section{DISCUSSION}

The study of international war veterans' physical health status, as well as the link between combat exposure, PTSD and physical health has been largely examined in the literature (Qureshi et al., 2009; Tansey et al., 2012). However, no systematic review is currently available regarding PCW veterans' physical health. Despite the negative historical (attempt to maintain the former Portuguese colonies) political (dictatorship), social (neglect from the civil society towards PCW veterans) and clinical (poor medical care right after the war) context after the PCW (Albuquerque et al., 1992), the absence of a systematic review about this topic reveals to be a major gap in the literature, considering that 45 years have passed since the end of the war, a period significantly longer when compared with recent major wars (i.e., Iraq and Afghanistan war). In order to fill this gap, the present review was conducted with the purpose to synthesize the data regarding PCW veterans' physical health. Thus, our main goals were to characterize the PCW veterans' physical health status; to verify the link between combat exposure and physical health, as well as PTSD and physical health; and to analyze the comparison results between PCW veterans with and without PTSD diagnosis in relation to physical health; as well as the comparison results between PCW veterans and general population in relation to the same outcome.

Studies showed that PCW veterans reported several physical complaints (e.g., headaches, fatigue, low back pain) and chronic diseases (e.g., cardiovascular diseases, gastrointestinal diseases) during (Começanha \& Maia, 2011) and after the PCW (Albuquerque et al., 1992; Albuquerque \& Lopes, 1994; Ferrajão, 2017; Maia et al., 2011; Pereira et al., 2010; Silva et al., 2010). In addition, PCW veterans reported several risk behaviors (i.e., alcohol, tobacco, coffee consumption, and drug use) (Albuquerque et al., 1992; Albuquerque \& Lopes, 1994; Maia et al., 2006) with the aim of reducing war-related discomfort (Maia et al., 2006). Lastly, PCW veterans reported the need of health services use (Começanha \& Maia, 2011; Ferrajão, 2017), which, as found by Ferrajão (2017), was done for the relief of psychological symptoms, or avoidance of symptoms associated with potentially traumatic events. Similar results were found in Vietnam, Iraq, and Afghanistan veterans regarding physical morbidity (Tansey et al., 2012), risk behaviors (Seal et al., 2011), and health services use (Frenk et al., 2017).

Taking into account the PCW veterans' reports, combat exposure and PTSD symptoms may have had an important impact on PCW veterans' physical health. In fact, Maia et al. (2011), in a sample of 350 PCW veterans, found that combat exposure was positively correlated with physical complaints and chronic diseases, and was a significant predictor of these outcomes. These results are similar with other empirical studies that indicated a significant positive association between combat exposure and the report of physical health problems in Vietnam, Afghanistan, and Iraq war veteran samples (Bourn et al., 2016; Buttner et al., 2017).

Regarding PTSD symptoms, two studies with PCW veteran samples showed that PTSD was related to physical morbidity (Começanha \& Maia, 2011; Maia et al., 2011). These results are in line with the findings obtained in a subsequent study by Osório et al. (2012), which found a significant relationship between PTSD and physical morbidity (e.g., fatigue, respiratory diseases) in a sample of 113 Portuguese Army Special Operation forces deployed in Afghanistan. One included study also highlighted the role of PTSD-specific clusters. Specifically, Maia et al. (2011) found that avoidance was the strongest predictor of chronic diseases, whereas arousal was the strongest predictor of physical complaints. These results were partly supported by previous research, who showed that hyper-arousal, a cluster with a strong physiological component, was the strongest predictor of physical morbidity (Hoge et al., 2007). These findings, however, were exclusive to physical morbidity. In two studies with PCW samples, PTSD was not associated neither with health services use (Começanha \& Maia, 2011), nor with physical quality of life (Pereira et al., 2012). These results are not in accordance with previous research (Painter, Gray, McGinn, Mostoufi, \& Hoerster, 2016). In relation to physical quality of life, Pereira et al. (2012) explained that the study sample was a very homogenous group, with high levels of somatization and poor physical quality of life. Thus, PTSD had a null effect on this variable. In relation to health services use, no explanation was given (Começanha \& Maia, 2011), however, the study small sample size $(N=50)$ could explain this result. In addition to these findings, Maia et al. (2011) found that PTSD was a mediator of the association between combat exposure and physical morbidity, thus revealing to be a possible key mechanism between trauma exposure and poor physical health. In this regard, Schnurr and Green (2004) proposed an integrative model in which PTSD may be the primary pathway by which trauma leads to negative health outcomes. This finding is in line with previous research (Schnurr \& Spiro, 1999), revealing the role of an early diagnosis and treatment of PTSD in war veterans for the prevention of later physical morbidity.

Finally, two studies found that PCW veterans showed a higher rate of physical morbidity compared to nonveterans (Começanha \& Maia, 2011, Couto, 2007), as well as a greater need of health services use (Couto, 2007). These findings are in accordance with previous research (Dunne, Burrell, Diggins, 
Whitehead, \& Latimer, 2015). In contrast, there was no significant differences between PCW veterans and nonveterans in relation to alcohol, tobacco, and coffee consumption. This finding was different from previous studies (Bachrach, Blosnich, \& Williams, 2018). Despite this inconsistent finding, overall, these results are in accordance with previous research that focuses on the direct contribution of trauma exposure on physical health, independent of PTSD symptomatology.

Biological, behavioral, and psychological mechanisms could also explain the link between combat exposure, PTSD, and physical health problems. For instance, the alterations in cortisol and catecholamine levels that are associated with PTSD could explain the increased susceptibility to some types of diseases, such as cardiovascular or autoimmune diseases (Boscarino, 2004). The long-term impact of physiological changes (PTSD symptom cluster hyper-arousal) in adaptation to chronic stress (i.e., allostatic load), may also have an important role in the relationship between combat exposure, PTSD and physical health (McEwen, 2000). To our knowledge, no studies with PCW veterans presented an objective to confirm these proposed models. Finally, the comorbidity between PTSD and negative affect (e.g., anger, depression) and risk behaviors could also explain the onset of physical morbidity (Friedman \& Schnurr, 1995). In fact, Maia et al. (2011) found that current psychological distress was a significant predictor of PCW veterans' physical morbidity, while being also associated with PTSD. Despite not being the focus of this study, the authors indicated that this variable could be construed as a potential mediator of the relationship between combat exposure and physical health, or as a mediator between PTSD and physical health. This hypothesis was partly confirmed by Pereira et al.'s (2012) study, in which psychopathology was a mediator of the association between PTSD and PCW veterans' physical quality of life. No study confirmed the association of risk behaviors and veterans' PTSD symptoms.

Despite the interesting results found, all studies have a cross-sectional design, and some presented small sample sizes (e.g., Começanha \& Maia, 2011). These limitations prevent the establishment of causality between variables and the generalization of the results. Likewise, only one study assessed the relationship between combat exposure and physical morbidity; two studies assessed the relation between PTSD symptoms and physical morbidity (Começanha \& Maia, 2011; Maia et al., 2011), and one assessed the relationship between PTSD and physical quality of life (Pereira et al., 2012). Given the scarcity of studies, some caution is needed regarding he interpretation of these results. In order to establish a causality between the variables and a more robust understanding of the link between combat exposure, PTSD and PCW veterans' physical health, future longitudinal studies with larger sample sizes are needed. We also identified knowledge gaps in the literature, specifically the absence of interventional studies regarding the treatment of PCW veterans' physical complaints, chronic diseases, or the reduction of risk behaviors. Such studies would present important findings for future research, namely, the development of prevention and treatment interventions. Furthermore, it would be important to find data regarding PCW veterans' satisfaction with health services care and use. These data would be important for the understanding of the best practices regarding the specific needs of this population. Another forgotten topic was the study about the potential consequences of aging on PCW veterans' physical health. Research has shown that the aging process interacts with the exposure to traumatic events by yielding unique psychological and physiological effects (Gagnon \& Hersen, 2000). In fact, it was observed that aging-related experiences (e.g., retirement, death of a spouse) and cognitive changes that occur during aging (e.g., reduction in memory) were appraised as deterioration in physical health among the elderly (Gagnon \& Hersen, 2000; Solomon, Helvitz, \& Zerach, 2009). Given this population is at a relatively advanced age, future studies should address this issue by assessing the impact of aging on PCW veterans' physical health. These data would be important for the establishment of policies that would prevent the perception of physical health deterioration and promote a successful PCW veterans' aging process.

Despite the scarcity of studies reviewed, some clinical and practical implications can be mentioned. Combat exposure has been shown to be directly related to physical health. Thus, health professionals should be aware of this relationship in order to make appropriate assessments and referrals to different medical specialists on veteran patients. Research has also shown that trauma exposure and PTSD symptoms may affect patient-provider interactions during healthcare visits regardless of whether healthcare providers ask about trauma, or patients reveal their trauma history (Hays \& Stanley, 1997). Therefore, health providers should be trained to recognize and address the psychological state of these patients, in order to facilitate the referring to appropriate health professionals specialized in this issue. PTSD has also been shown to be a mediator variable of the association between combat exposure and poor physical health. This empirical finding means that PTSD symptoms could be a potential key mechanism through which adverse physical health outcomes are later developed. In order to prevent or treat physical health problems, mental health professionals should also consider the treatment of PCW veterans with a PTSD diagnosis. There are evidence-based psychotherapy treatments for PTSD (Forbes et 
al., 2010), therefore, mental health professionals experienced in working with PTSD patients may help to mitigate physical morbidity, improve perceived health, and mitigate the use of health services. It should be noted that veterans may experience other mental disorders in comorbidity with PTSD. Thus, health professionals should be aware of this issue in order to choose the appropriate treatments.

\section{Strengths and limitations}

To our knowledge, this is the first review that synthesizes the breadth of knowledge available regarding PCW veterans' physical health. This reveals to be the major strength of the present review. The inclusion of English and Portuguese language peer-reviewed journals, and unpublished gray literature (e.g., masters' thesis, unpublished empirical studies), regardless of year of publication and study design, reveals to be another possible strength of the current review, since prevents potential publication bias. However, the inclusion of data from unpublished studies can itself be a source of bias, given the absence of peer-review editors, which, consequently, may allow the analysis of lower methodological quality studies compared with published studies. Efforts were made to capture all relevant articles through contact with subject matter experts and consulting the references from the eligible studies; however, it is possible that articles were overlooked. The initial identification of relevant studies, through title and abstract, by one reviewer, is also a limitation, given that it was not conducted and confirmed by another reviewer, causing a possible source of bias. The inclusion of studies with overlapping samples (Couto, 2007; Maia et al., 2006, 2011) reveals to be another possible limitation of the present study (i.e., in a review, it is not advisable to present studies with similar results). However, these studies were included because each one presented clearly independent data regarding PCW veterans' physical health, which were not present in the remaining studies. The key findings from the current review may not be representative of all veterans who have served in the PCW, given the convenience sampling methods and small sample sizes from the included studies. Finally, this review did not exclude studies with poor overall assessment. Despite serving to identify main weakness, this reveals to be a possible limitation, because of their high risk of bias and negative influence in the interpretation of the results.

\section{Conclusion}

Overall, results indicated that both combat exposure and PTSD symptomatology might have contributed to the report of physical health problems in PCW veterans. The results also point to the fact that PCW veterans, especially those with PTSD diagnosis, were at increased risk of poorer physical health status compared to nonveterans. In addition, PTSD might be a key mechanism through which PCW veterans develop physical health problems after the exposure to combat stressors.

Despite the relevant results found, understudied content areas still exist. Notably, descriptive and observational research examining PCW veterans' physical health is much more developed compared with longitudinal or interventional research designs. Future studies may advance the field of research regarding PCW veterans' physical health with the purpose of guiding clinicians and policymakers in methods, which fully address the unique mental and physical health needs of a population that is at a relatively advanced age of life.

\section{REFERENCES}

Agha, Z., Lofgren, R. P., VanRuiswyk, J. V., \& Layde, P. M. (2000). Are patients at Veterans Affairs medical centers sicker?: A comparative analysis of health status and medical resource use. Archives of Internal Medicine, 160, 3252-3257. doi:10.1001/archinte.160.21.3252

Albuquerque, A., Fernandes, A., Saraiva, E., \& Lopes, F. (1992). Distúrbios pós-traumáticos do stress em ex-combatentes da guerra colonial [Posttraumatic stress disorders in Colonial war veterans]. Revista Psicologia Militar, 1, 399-407.

Albuquerque, A., Lopes, F. (1994). Características de um grupo de 120 ex-combatentes da guerra colonial vítimas de <<stress de guerra>> [Characteristics of a group of 120 colonial war veterans victims of < stress of war >>]. Vértice, 58, 28-32.

American Psychiatric Association. (2013). Diagnostic and statistical manual of mental disorders (5th ed.). Arlington, VA: American Psychiatric Association.

Bachrach, R. L., Blosnich, J. R., \& Williams, E. C. (2018). Alcohol screening and brief intervention in a representative sample of veterans receiving primary care services. Journal of Substance Abuse Treatment, 95, 18-25. doi:10.1016/j.jsat.2018.09.003

Beckham, J. C., Moore, S. D., Feldman, M. E., Hertzberg, M. A., Kirby, A. C., \& Fairbank, J. A. (1998). Health status, somatization, and severity of posttraumatic stress disorder in Vietnam combat veterans with posttraumatic stress disorder. American Journal of Psychiatry, 155, 1565-1569. doi:10.1176/ajp.155.11.1565 
Boscarino, J. A. (2004). Posttraumatic stress disorder and physical illness: Results from clinical and epidemiologic studies. Annals of the New York Academy of Sciences, 1032, 141-153. doi:10.1196/annals.1314.011

Bourn, L. E., Sexton, M. B., Raggio, G. A., Porter, K. E., \& Rauch, S. A. (2016). Posttraumatic stress disorder and somatic complaints: Contrasting Vietnam and OIF/OEF Veterans' experiences. Journal of Psychosomatic Research, 82, 35-40. doi:10.1016/j.jpsychores.2016.01.009

Buckley, T. C., Mozley, S. L., Bedard, M. A., Dewulf, A. C., \& Greif, J. (2004). Preventive health behaviors, health-risk behaviors, physical morbidity, and health-related role functioning impairment in veterans with post-traumatic stress disorder. Military Medicine, 169, 536-540. doi:10.7205/MILMED.169.7.536

Buttner, M. M., Godfrey, K. M., Floto, E., Pittman, J., Lindamer, L., \& Afari, N. (2017). Combat exposure and pain in male and female Afghanistan and Iraq veterans: The role of mediators and moderators. Psychiatry Research, 257, 7-13. doi:10.1016/j.psychres.2017.07.001

Começanha, R., \& Maia, A. (2011). Determinantes da utilização de serviços de saúde em ex-combatentes da Guerra Colonial Portuguesa: Estresse pós-traumático, neuroticismo e apoio social [Determinants of health services use in Portuguese Colonial War veterans: Post-traumatic stress, neuroticism and social support]. Contextos Clínicos, 4, 123-131. doi:10.4013/ctc.2011.42.06

Couto, M. J. (2007). Exposição a trauma e caracterização do ajustamento psicológico, de saúde, familiar e laboral de uma amostra de homens portugueses: Um estudo comparativo entre ex-combatentes da guerra colonial e um grupo da mesma idade sem essa experiência [Trauma exposure and the characterization of psychological adjustment, health, family and work indicators in a sample of portuguese men: A comparative study among veterans of the colonial war and their nonveteran cohorts] (Unpublished master thesis). Universidade do Minho, Braga, Portugal

Critical Appraisal Skills Programme. (2013). CASP checklists. Available at: http://www.casp-uk.net/. Accessed 10 November, 2018.

Cucciare, M. A., Darrow, M., \& Weingardt, K. R. (2011). Characterizing binge drinking among US military Veterans receiving a brief alcohol intervention. Addictive Behaviors, 36, 362-367. doi:10.1016/j.addbeh.2010.12.014

Dunne, E. M., Burrell, L. E., Diggins, A. D., Whitehead, N. E., \& Latimer, W. W. (2015). Increased risk for substance use and health-related problems among homeless veterans. The American Journal on Addictions, 24, 676-680. doi:10.1111/ajad.12289

Durai, U. N. B., Chopra, M. P., Coakley, E., Llorente, M. D., Kirchner, J. E., Cook, J. M., \& Levkoff, S. E. (2011). Exposure to trauma and posttraumatic stress disorder symptoms in older veterans attending primary care: Comorbid conditions and self-rated health status. Journal of the American Geriatrics Society, 59, 1087-1092. doi:10.1111/j.1532-5415.2011.03407.x

Dursa, E. K., Barth, S. K., Schneiderman, A. I., \& Bossarte, R. M. (2016). Physical and mental health status of Gulf War and Gulf Era veterans: Results from a large population-based epidemiological study. Journal of Occupational and Environmental Medicine, 58, 41-46. doi:10.1097/JOM.0000000000000627

Edmondson, D., \& von Känel, R. (2017). Post-traumatic stress disorder and cardiovascular disease. The Lancet Psychiatry, 4, 320-329. doi:10.1016/S2215-0366(16)30377-7

Ferrajão, P. C. (2017). Pathways between combat stress and physical health among Portuguese war veterans. Qualitative Health Research, 27, 1640-1651. doi:10.1177/1049732317701404

Forbes, D., Creamer, M., Bisson, J. I., Cohen, J. A., Crow, B. E., Foa, E. B., ... Ursano, R. J. (2010). A guide of guidelines for the treatment of PTSD and related conditions. Journal of Traumatic Stress, 23, 537552. doi:10.1002/jts.20565

Frenk, S. M., Sautter, J. M., Woodring, J. V., \& Kramarow, E. A. (2017). Veteran status, sociodemographic characteristics, and healthcare factors associated with visiting a mental health professional. Community Mental Health Journal, 53, 515-524. doi:10.1007/s10597-016-0071-x

Friedman, M. J., \& Schnurr, P. P. (1995). The relationship between trauma, posttraumatic stress disorder, and physical health. In M. J. Friedman, D. S. Charney, \& A. Y. Deutch (Eds.), Neurobiological and clinical consequences of stress (pp. 507-524). Philadelphia: Lippincott-Raven.

Gagnon, M., \& Hersen, M. (2000). Unresolved childhood sexual abuse and older adults: Late-life vulnerabilities. Journal of Clinical Geropsychology, 6, 187-198. doi:10.1023/A:1009589115942

Hassija, C. M., Jakupcak, M., Maguen, S., \& Shipherd, J. C. (2012). The influence of combat and interpersonal trauma on PTSD, depression, and alcohol misuse in US Gulf War and OEF/OIF women veterans. Journal of Traumatic Stress, 25, 216-219. doi:10.1002/jts.21686

Hays, K. F., \& Stanley, S. F. (1997). The impact of childhood sexual abuse on women's dental experiences. Journal of Child Sexual Abuse, 5, 65-67. doi:10.1300/J070v05n04_04 
Hoge, C. W., Terhakopian, A., Castro, C. A., Messer, S. C., \& Engel, C. C. (2007). Association of posttraumatic stress disorder with somatic symptoms, health care visits, and absenteeism among Iraq war veterans. American Journal of Psychiatry, 164, 150-153. doi:10.1176/ajp.2007.164.1.150

Ismaeel, A., Weems, S., Ellor, J. W., Crow, J., Myers, D., Dolan, S., ... Morissette, S. B. (2018). Association between negative emotional states and unhealthy nutritional behaviors in soldiers. Military Behavioral Health, 6, 66-74. doi:10.1080/21635781.2017.1337597

Kang, H. K., Natelson, B. H., Mahan, C. M., Lee, K. Y., \& Murphy, F. M. (2003). Post-traumatic stress disorder and chronic fatigue syndrome-like illness among Gulf War veterans: A population-based survey of 30,000 veterans. American Journal of Epidemiology, 157, 141-148. doi:10.1093/aje/kwf187

Keane, T. M., Fairbank, J. A., Caddell, J. M., Zimering, R. T., Taylor, K. L., \& Mora, C. A. (1989). Clinical evaluation of a measure to assess combat exposure. Psychological Assessment, 1, 53-55. doi:10.1037/1040-3590.1.1.53

Klingaman, E. A., Hoerster, K. D., Aakre, J. M., Viverito, K. M., Medoff, D. R., \& Goldberg, R. W. (2016). Veterans with PTSD report more weight loss barriers than veterans with no mental health disorders. General Hospital Psychiatry, 39, 1-7. doi:10.1016/j.genhosppsych.2015.11.003

Lehavot, K., Der-Martirosian, C., Simpson, T. L., Shipherd, J. C., \& Washington, D. L. (2013). The role of military social support in understanding the relationship between PTSD, physical health, and healthcare utilization in women veterans. Journal of Traumatic Stress, 26, 772-775. doi:10.1002/jts.21859

Liberati, A., Altman, D. G., Tetzlaff, J., Mulrow, C., Gøtzsche, P. C., Ioannidis, J. P., ... Moher, D. (2009). The PRISMA statement for reporting systematic reviews and meta-analyses of studies that evaluate health care interventions: Explanation and elaboration. PLoS Medicine, 6, e1-e34. doi:10.1371/journal.pmed.1000100

López-Martínez, A. E., Serrano-Ibáñez, E. R., Ruiz-Párraga, G. T., Gómez-Pérez, L., Ramírez-Maestre, C., \& Esteve, R. (2018). Physical health consequences of interpersonal trauma: A systematic review of the role of psychological variables. Trauma, Violence, \& Abuse, 19, 305-322. doi:10.1177/1524838016659488

Maia, A., McIntyre, T., Pereira, G., \& Fernandes, E. (2006). Por baixo das pústulas da guerra: Reflexões sobre um estudo com ex-combatentes da guerra colonial [Under the pustules of war: Reflections on a study with colonial war veterans]. In Centro de Estudos Lusíadas/ Universidade do Minho, (ed.), A Guerra Colonial (1961-1974) (pp. 11-28). Braga, Portugal.

Maia, A., McIntyre, T., Pereira, M. G., \& Ribeiro, E. (2011). War exposure and post-traumatic stress as predictors of Portuguese colonial war veterans' physical health. Anxiety, Stress, \& Coping, 24, 309325. doi:10.1080/10615806.2010.521238

McDevitt-Murphy, M. E., Fields, J. A., Monahan, C. J., \& Bracken, K. L. (2015). Drinking motives among heavy-drinking veterans with and without posttraumatic stress disorder. Addiction Research \& Theory, 23, 148-155. doi:10.3109/16066359.2014.949696

McEwen B. S. (2000). Allostasis and allostatic load: Implications for neuropsychopharmacology. Neuropsychopharmacology, 22, 108-124. doi:10.1038/sj.npp.1395453

McFarlane, A. C., Weber, D. L., \& Clark, C. R. (1993). Abnormal stimulus processing in posttraumatic stress disorder. Biological Psychiatry, 34, 311-320. doi:10.1016/0006-3223(93)90088-U

McHugh, M. L. (2012). Interrater reliability: The kappa statistic. Biochemia Medica, 22, 276-282. doi:10.11613/BM.2012.031

Nakamura, Y., Lipschitz, D. L., Donaldson, G. W., Kida, Y., Williams, S. L., Landward, R., ... Tuteja, A. K. (2017). Investigating clinical benefits of a novel sleep-focused mind-body program on Gulf War illness symptoms: A randomized controlled trial. Psychosomatic Medicine, 79, 706-718. doi:10.1097/PSY.0000000000000469

National Institutes of Health (2016). National Institutes of Health Quality Assessment tool for Observational Cohort and Cross-Sectional Studies. Available online at: http://www.nhlbi.nih.gov/healthpro/guidelines/in-develop/cardiovascular-risk-reduction/tools/cohort (Accessed 10 November, 2018).

Osório, C., Carvalho, C., Fertout, M., \& Maia, Â. (2012). Prevalence of post-traumatic stress disorder and physical health complaints among Portuguese Army Special Operations Forces deployed in Afghanistan. Military Medicine, 177, 957-962. doi:10.7205/MILMED-D-12-00024

Painter, J. M., Gray, K., McGinn, M. M., Mostoufi, S., \& Hoerster, K. D. (2016). The relationships of posttraumatic stress disorder and depression symptoms with health-related quality of life and the role of social support among Veterans. Quality of Life Research, 25, 2657-2667. doi:10.1007/s11136-016-1295-5 
Pereira, M. G., Pedras, S., \& Lopes, C. (2012). Posttraumatic stress, psychological morbidity, psychopathology, family functioning, and quality of life in Portuguese war veterans. Traumatology, 18, 49-58. doi.10.1177/1534765611426794

Pereira, M, G., Pedras, S., Lopes, C., Pereira, M., Machado, J,C. (2010). Saúde mental, doença, tipo de familía, suporte social e qualidade de vida em veteranos da guerra colonial portuguesa [Mental health, disease, family type, social support and quality of life in Portuguese colonial war veterans]. In Do Diagnóstico à Intervenção em Saúde Mental: II Congresso Internacional da SPESM. A Sociedade Portuguesa de Enfermagem de Saúde Mental (ASPESM), 319-330.

Peters, A., McEwen, B. S., \& Friston, K. (2017). Uncertainty and stress: Why it causes diseases and how it is mastered by the brain. Progress in Neurobiology, 156, 164-188. doi:10.1016/j.pneurobio.2017.05.004

Qureshi, S. U., Pyne, J. M., Magruder, K. M., Schulz, P. E., \& Kunik, M. E. (2009). The link between posttraumatic stress disorder and physical comorbidities: A systematic review. Psychiatric Quarterly, 80, 87-97. doi:10.1007/s11126-009-9096-4

Schnurr, P. P., \& Green, B. L. (2004). Understanding relationships among trauma, post-traumatic stress disorder, and health outcomes. Advances in Mind-Body Medicine, 20, 18-29. doi:10.1037/10723010

Schnurr, P. P., \& Spiro, A. (1999). Combat exposure, posttraumatic stress disorder symptoms, and health behaviors as predictors of self-reported physical health in older veterans. The Journal of Nervous and Mental Disease, 187, 353-359. doi:10.1097/00005053-199906000-00004

Seal, K. H., Cohen, G., Waldrop, A., Cohen, B. E., Maguen, S., \& Ren, L. (2011). Substance use disorders in Iraq and Afghanistan veterans in VA healthcare, 2001-2010: Implications for screening, diagnosis and treatment. Drug and Alcohol Dependence, 116, 93-101. doi:10.1016/j.drugalcdep.2010.11.027

Silva, J. A., Brito, B., Silva, M. R., Borges, M., Romão, A., Queiroz, S. M., ... Santos, A. S. (2010). Feridas de Guerra: (In) justiça silenciada. [Wounds of War: (In) Silenced (In)Justice.]. Retrieved from http://www.aofa.pt/rimp/Relatorio_MDN.pdf

Sledjeski, E. M., Speisman, B., \& Dierker, L. C. (2008). Does number of lifetime traumas explain the relationship between PTSD and chronic medical conditions? Answers from the National Comorbidity Survey-Replication (NCS-R). Journal of Behavioral Medicine, 3, 341-349. doi:10.1007/s10865-008-9158-3

Solomon, Z., Helvitz, H., \& Zerach, G. (2009). Subjective age, PTSD and physical health among war veterans. Aging and Mental Health, 13, 405-413. doi:10.1080/13607860802459856

Tansey, C. M., Raina, P., \& Wolfson, C. (2012). Veterans' physical health. Epidemiologic Reviews, 35, 66-74. doi:10.1093/epirev/mxs005

Weiss, S. J. (2007). Neurobiological alterations associated with traumatic stress. Perspectives in Psychiatric Care, 43, 114-122. doi:10.1111/j.1744-6163.2007.00120.x.

$\begin{array}{lr}\text { Historial do } & \text { artigo } \\ \text { Recebido } & 01 / 2019 \\ \text { Aceite } & 12 / 2019 \\ \text { Publicado } & 12 / 2019\end{array}$


Portuguese Colonial War veterans' physical health 